J. Clin. Chem. Clin. Biochem.

Vol. 24, 1986, pp. 185-188

(C) 1986 Walter de Gruyter \& Co. Berlin - New York

\title{
Determination of Catecholamines in Plasma by HPLC and Amperometric Detection. Comparison with a Radioenzymatic Method
}

\author{
By W. Bauersfeld, D. Ratge, E. Knoll and H. Wisser \\ Abteilung für Klinische Chemie - Labormedizin - Robert-Bosch-Krankenhaus Stuttgart
}

(Received March 29/September 23/December 12, 1985)

\begin{abstract}
Summary: The determination of norepinephrine and epinephrine in plasma by HPLC with amperometric detection was modified, giving detection limits of $25 \mathrm{ng} / 1$ and $18 \mathrm{ng} / 1$ for norepinephrine and epinephrine, respectively, using $1 \mathrm{ml}$ plasma. In order to achieve this sensitivity, it was necessary to minimize the background noise by modification of instrumentation and specimen handling. Particularly important was the extra purification of the reagents, the application of micro-bore HPLC, the enzymatic cleavage of uric acid and temperature control of the amperometric cell and the amplifier. Comparison of the present method with the radioenzymatic determination of catecholamines resulted in coefficients of correlation of $r=0.924$ and 0.919 for norepinephrine and epinephrine, resp. $(n=38)$. The concentrations of the 38 different samples used for the comparison were in the physiological range.
\end{abstract}

Bestimmung der Katecholamine im Plasma durch HPLC und amperometrische Detektion - Vergleich mit einer radioenzymatischen Methode

Zusammenfassung: Die Bestimmung von Noradrenalin und Adrenalin im Plasma mit HPLC und amperometrischer Detektion wurde so modifiziert, daß - bei einem Probenvolumen von $1 \mathrm{ml}$ Plasma - eine Nachweisgrenze von $25 \mathrm{ng} / 1$ für Noradrenalin und von $18 \mathrm{ng} / 1$ für Adrenalin erreicht wurde. Diese Empfindlichkeit konnte durch Erniedrigung des Untergrundrauschens erreicht werden, indem die Meßapparatur und die Probenaufarbeitung modifiziert wurden. Besonders wichtig sind hierbei die Reinigung der verwendeten Reagenzien, die Verwendung von „micro-bore“-Säulen, die enzymatische Spaltung der Harnsäure sowie die Temperierung der amperometrischen Zelle und des Verstärkers. Bei dem Vergleich der hier beschriebenen Methode mit der radioenzymatischen Methode ergaben sich Korrelationskoeffizienten von $r=0,924$ und 0,919 für Noradrenalin und Adrenalin $(n=38)$, wobei die Katecholaminkonzentrationen in allen Proben im physiologischen Bereich waren.

\section{Introduction}

The determination of catecholamines in plasma by HPLC and amperometric detection has been described by several authors (for review see l. c. $(1-6)$. They have used sample volumes ranging from 0.75 to $4 \mathrm{ml}$ of plasma for each determination. The sensitivity of these methods is inadequate for determination of resting values of epinephrine, even if $4 \mathrm{ml}$ of plasma are used. Moreover, there are great differences in the concentrations determined by HPLC with amperometric detection versus those measured with a radioenzymatic method (7). The aim of the present study was the development of a method for the determination of norepinephrine and epinephrine in plasma which combines both simple handling and sufficient sensitivity. 
This goal seemed to be reasonable in view of the fact that an electrochemical method requires no tritiated compounds and is more amenable to mechanization (thereby increasing sample frequency) than the time consuming radioenzymatic method.

\section{Methods \\ Principle of the method}

The catecholamines are separated from the plasma matrix by adsorption on alumina at a high $\mathrm{pH}$ followed by selective desorption using a mixture of boric and acetic acid. The separation and quantification of the extracted catecholamines is performed by micro-bore HPLC with amperometric detection. As uric acid is eluted at the front of the chromatogram, the enzymatic cleavage of uric acid is performed to avoid interference with norepinephrine.

\section{Equipment}

Details of the measuring equipment have been described by Bauersfeld et al. (8).

\section{Chemicals and reagents}

Alumina, neutral 70-200 mesh (Merck, Darmstadt), was purified and activated as described by Anton \& Sayre (9). Sodium sulphate p. a. (Merck) was extracted with a solution of dithizon in chloroform to remove traces of heavy metals. Boric acid p. a. (Merck): a saturated solution of boric acid was extracted with ethyl acetate and recrystallised. Water was purified by distilling over sodium permanganate. Solutions were prepared acc. to Bauersfeld et al. (8).

\section{Methodology}

To $1 \mathrm{ml}$ of plasma were added $100 \mu$ l of solution B (8), $100 \mu \mathrm{l}$ of $2 \mathrm{~mol} / 1$ Tris solution and $50 \mu \mathrm{l}$ of $20 \mathrm{U} / 1$ uricase solution. After $10 \mathrm{~min}, 10 \mathrm{mg}$ of alumina were added and cautiously mixed for $15 \mathrm{~min}$ using an inverting mixer. Next, the samples were centrifuged at $15000 \mathrm{~g}$ for $30 \mathrm{~s}$. The upper layer was aspirated and discarded. The alumina was then washed twice with $500 \mu$ l of solution F. A final washing was performed with $500 \mu \mathrm{l}$ of water. Following centrifugation, the washing solution was drawn off once again.

Following the addition of $50 \mu$ l of solution $\mathrm{E}$, the samples were agitated for $5 \mathrm{~min}$, then centrifuged at $15000 \mathrm{~g}$ for $2 \mathrm{~min}$, after which each solution was transferred to another Eppendorf vial. These eluates were then stored at $4{ }^{\circ} \mathrm{C}$ until HPLC measurement. A final centrifugation at $15000 \mathrm{~g}$ for 2 min was performed immediately preceding injection of $20 \mu$ l of the eluates.

The HPLC separation was performed using a micro-bore column; mobile phase: $42 \mathrm{mmol} / 1$ acetic acid, $1 \mathrm{mmol} / 1$ butylamine, $0.8 \mathrm{mmol} / 1$ sodium octylsulphonate, $0.05 \mathrm{mmol} / 1$ disodiumEDTA, $10 \mathrm{mmol} / \mathrm{l}$ sodium sulphate. The flow rate was $300 \mu \mathrm{l} /$ $\min$. The amperometric detector was set to an oxidizing potential of $650 \mathrm{mV}$ and a sensitivity of $0.5 \mathrm{nA}$ at full scale. The recovery of each sample was determined using the peak heights of the internal standards (3,4-dihydroxybenzylamine or epinine).

\section{Radioenzymatic method}

For the comparative radioenzymatic measurements the method of Ratge et al. (10) was used.

\section{Results and Discussion}

The within-run and between-run precision was estimated by $n=10$ measurements of plasma samples containing the catecholamines in physiological concentrations (tab. 1). The results are comparable to those obtained with the radioenzymatic method used routinely in our laboratory (10). The recovery of norepinephrine was $99.1 \%$ (range $83.1-106.9 \%$ ) and of epinephrine $96.0 \%$ (range $88.2-109.3 \%$ ). The linear measuring range was 40 to $1200 \mathrm{ng} / \mathrm{l}$ for norepinephrine and 20 to $1200 \mathrm{ng} / \mathrm{l}$ for epinephrine, resp. Thirty eight different serum samples were analysed with the present method and with the radioenzymatic method. The concentration of catecholamines in these samples were in the physiological range. The results of the comparison are shown in figures $1 \mathrm{a}$ and $1 \mathrm{~b}$. Statistical evaluation resulted in a regression line of $\mathrm{y}=0.924 \mathrm{x}+5.5 \mathrm{ng} / \mathrm{l}(\mathrm{r}=0.921)$ for norepinephrine and $y=0.919 x+2.8 \mathrm{ng} / \mathrm{l}(\mathrm{r}=0.923)$ for epinephrine ( $x=$ radioenzymatic method).

Tab. 1. Within run and between day precision of the plasma catecholamine determination by HPLC combined with amperometric detection.

\begin{tabular}{lcc}
\hline & Norepinephrine & Epinephrine \\
\hline Within run $(\mathrm{n}=10)$ & & \\
$\overline{\mathrm{x}}(\mathrm{ng} / \mathrm{l})$ & 144.2 & 68.5 \\
$\mathrm{~s}(\mathrm{ng} / \mathrm{l})$ & 5.3 & 4.9 \\
CV $(\%)$ & 3.7 & 7.2 \\
& & \\
Between day $(\mathrm{n}=10)$ & & \\
$\overline{\mathrm{x}}(\mathrm{ng} / \mathrm{l})$ & 173.0 & 59.6 \\
$\mathrm{~s}(\mathrm{ng} / \mathrm{l})$ & $16.6^{\circ}$ & 7.7 \\
CV $(\%)$ & 9.6 & 13.0 \\
\hline
\end{tabular}

\section{Specificity}

A large number of compounds were added, in order to evaluate their potential interference with the determination of norepinephrine and epinephrine. No interference by any of the tested compounds (normetanephrine, metanephrine, 3-methoxytyramine, 3-methoxy-4-hydroxyphenylglycol, vanilmandelic acid, homovanillic acid, tyramine, octopamine, synephrine, 3,4-dihydroxymandelic acid, 3,4-dihydroxyphenylalanine, 3,4-dihydroxyphenylglycol, serotonin, kynurenine, 3-hydroxykynurenine and tryptamine) was observed.

\section{Sensitivity}

The detection limit was estimated to be $25 \mathrm{ng} / \mathrm{l}$ and $18 \mathrm{ng} / \mathrm{l}$ for norepinephrine and epinephrine, resp., when defined as the concentration equivalent to three times the baseline noise. 

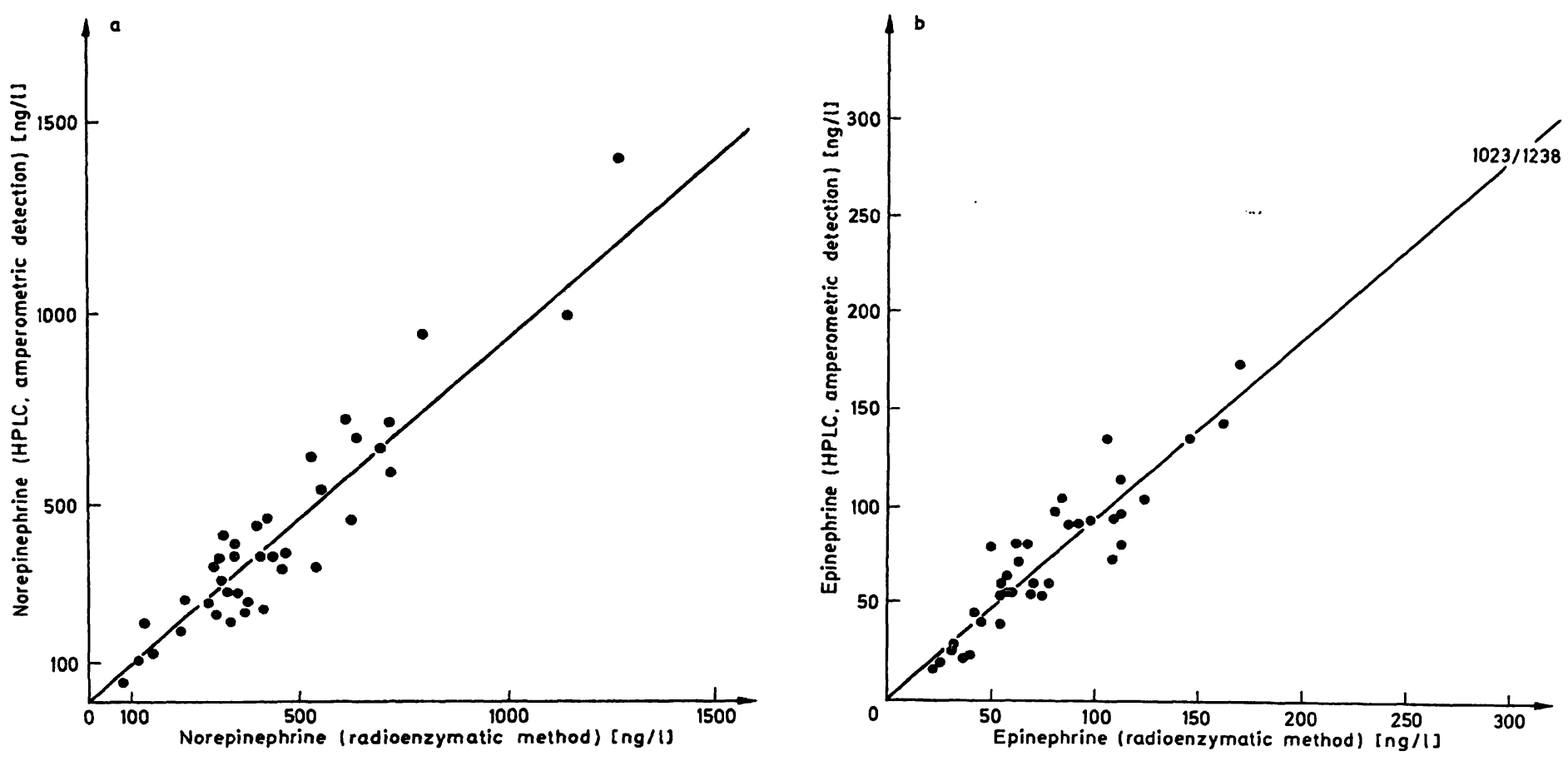

Fig. 1. Comparison of the determination of norepinephrine (1 a) and epinephrine (1 b) by HPLC and amperometric detection (ordinate) with a radioenzymatic method (abscissa). $\mathrm{y}=0.924 \mathrm{x}+5.5 \mathrm{ng} / \mathrm{l}, \mathrm{r}=0.921, \mathrm{n}=38$ (norepinephrine) $\mathrm{y}=0.919 \mathrm{x}+2.8 \mathrm{ng} / \mathrm{l}, \mathrm{r}=0.923, \mathrm{n}=38$ (epinephrine)

To compare the sensitivity of our method with that of other publications that define the detection limit as three times the baseline noise of aqueous catecholamine solutions, we obtained values of $3.5 \mathrm{pg}$ norepinephrine and $4.0 \mathrm{pg}$ epinephrine, for the detection limits.

\section{Practicability}

The time required for each chromatogram was 30 min. The sample frequency was determined to be $\mathbf{4 0}$ samples/day, presuming the use of a programmecontrolled sample injector. Pre-purification of 12 samples required about one hour and the evaluation of the chromatograms an additional hour.

\section{Clinical application of the method}

The sensitivity of the presented method is adequate for measuring norepinephrine and epinephrine in the range of physiological plasma concentrations. A typical chromatogram of a sample from a healthy volunteer is shown in figure 2 (left). The marked peaks correspond to concentrations of $194 \mathrm{ng} / \mathrm{l}$ and $57 \mathrm{ng} / \mathrm{l}$ of norepinephrine and epinephrine, resp. A chromatogram of a sample from a patient with a phaeochromocytoma is shown in figure 2 (right). The peaks correspond to concentrations of $1292 \mathrm{ng} / \mathrm{l}$ and 1023 $\mathrm{ng} / \mathrm{l}$ of norepinephrine and epinephrine, resp.
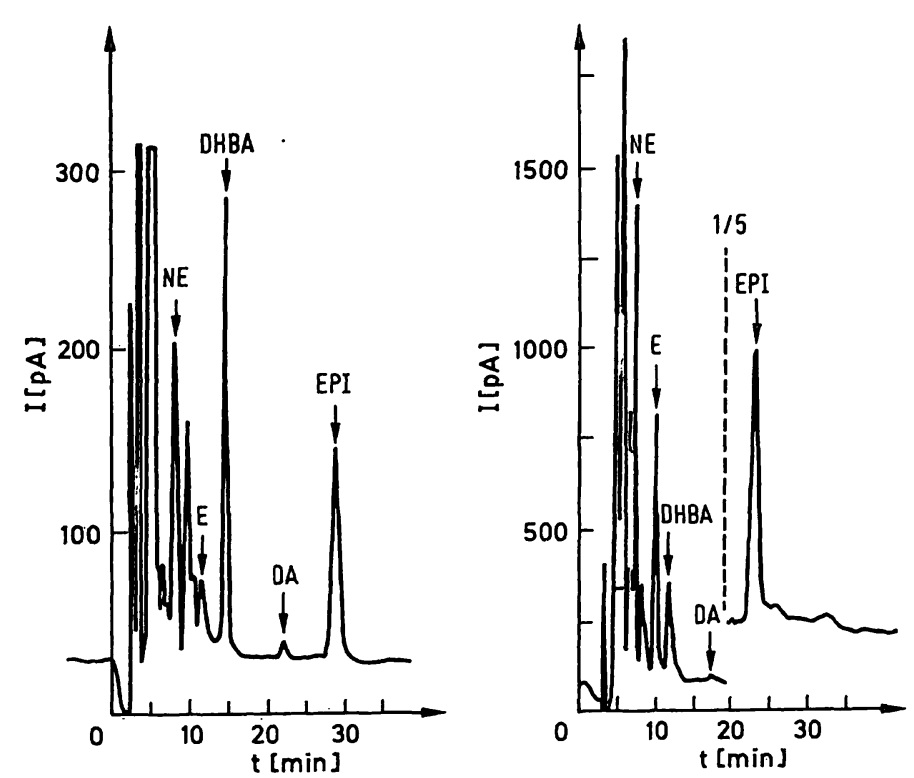

Fig. 2. Typical chromatograms obtained by the present method.

Left: Chromatogram of a healthy volunteer (194 ng/l norepinephrine, $57 \mathrm{ng} / \mathrm{l}$ epinephrine).

Right: Chromatogram of a patient with a phaeochromocytoma $(1292 \mathrm{ng} / \mathrm{l}$ norepinephrine, $1023 \mathrm{ng} / \mathrm{l}$ epinephrine).

In the first part of the second chromatogram the sensitivity of the detector was reduced to an amplification ratio of $20 \%$.

$(\mathrm{E}=$ epinephrine; $\mathrm{NE}=$ norepinephrine;

$\mathrm{DA}=$ dopamine; EPI = Epinine;

DHBA = 3,4-dihydroxybenzylamine). 
The increase in sensitivity of the present method results from several modifications to instrumentation and handling. The use of a micro-bore column permitting low flow rates, of a detector capable of controlling the temperature of the thin layer cell, and of an amplifier generating reduced electronic noise results in a significant increase in the sensitivity of the method. As the separation of norepinephrine from uric acid by HPLC is generally difficult, enzymatic cleavage of uric acid is utilized to avoid this chromatographic problem. The elution of catecholamines from alumina by a mixture of boric and acetic acid also increases the selectivity of the method. This is demonstrated by the fact that the interferences with epinephrine and 3,4-dihydroxybenzylamine which can be observed by elution with perchloric acid, are not observed when a mixture of boric acid and acetic acid is employed.

Dual electrochemical detectors (11) may be more selective than simple amperometric detectors, but it was impossible to separate interferants like uric acid in this way.

The excellent correlation of the two methods evaluated in the present study demonstrates the necessity of the described modifications. It should also be remembered that each measurement presented in this study was accomplished using a sample volume of $1 \mathrm{ml}$, which is a quarter of the volume required in most previously published procedures.

Another advantage of this method is the simplified handling compared with radioenzymatic methods. A sample frequency of 40 samples per day can be achieved with 8 hours being needed for the pre-purification of the samples and the final evaluation of the chromatograms. If samples from different patients are estimated by the radioenzymatic method, enzymatic recovery must be determined for each sample, and only 25 samples can be measured in 12 hours over two days.

\section{References}

1. Allenmark, S. (1982) J. Liquid Chromatogr. 5, Suppl. 1, $1-41$.

2. Holly, J. M. P. \& Makin, H. L. J. (1982) Anal. Biochem. $128,257-274$.

3. Davis, G. C., Kissinger, P. T. \& Shoup, R. E. (1981) Anal. Chem. 53, 156-159.

4. Krstulovic, A. M. (1982) J. Chromatogr. 229, 1-34.

5. Mefford, I. N. (1981) J. Neurosci. Meth. 3, 207-224.

6. Ratge, D. \& Wisser, H. (1983) Ärztl. Lab. 29, 209-214.

7. Causon, R. C., Brown, M. M., Boulous, P. M. \& Perret, D. (1983) Clin. Chem. 29, 735-737.

8. Bauersfeld, W., Ratge, D., Knoll, E. \& Wisser, H. (1984) Fresenius Z. Anal. Chem. 317, 679-680.

9. Anton, A. H. \& Sayre, D. F. (1962) J. Pharmacol. Exp. Therapeut. $138,360-374$.

10. Ratge, D., Baumgardt, G., Knoll, E. \& Wisser, H. (1983) Clin. Chim. Acta 132, 229-243.

11. Goto, M., Sakurai, E. \& Ishi, D. (1982) J. Chromatogr. $238,357-366$.

Prof. Dr. Dr. H. Wisser

Abteilung für Klinische Chemie

- Labormedizin -

Robert-Bosch-Krankenhaus

Auerbachstraße 110

D-7000 Stuttgart 50 